\title{
Angiotensin-(1-7) stimulates cholesterol efflux from angiotensin II-treated cholesterol-loaded THP-1 macrophages through the suppression of p38 and c-Jun $\mathrm{N}$-terminal kinase signaling
}

\author{
HUI-YU YANG, YUN-FEI BIAN, CHUAN-SHI XIAO, BIN LIANG, NANA ZHANG, \\ FEN GAO and ZHI-MING YANG
}

Department of Cardiology, The Second Hospital of Shanxi Medical University, Taiyuan, Shanxi 030001, P.R. China

Received May 10, 2014; Accepted January 23, 2015

DOI: $10.3892 / \mathrm{mmr} .2015 .3484$

\begin{abstract}
Angiotensin II (Ang II) and Ang-(1-7) are key effector peptides of the renin-angiotensin system. The present study aimed to investigate the effects of Ang-(1-7) on Ang II-stimulated cholesterol efflux and the associated molecular mechanisms. Differentiated THP-1 macrophages were treated with Ang II (1 $\mu \mathrm{M})$ and/or Ang-(1-7) (10 and $100 \mathrm{nM})$ for $24 \mathrm{~h}$ and the cholesterol efflux and gene expression levels were assessed. Pharmacological inhibition of peroxisome proliferator-activated receptor (PPAR) $\gamma$ and mitogen-activated protein kinases (MAPKs) were performed to identify the signaling pathways involved. The results demonstrated that Ang II significantly inhibited the cholesterol efflux from cholesterol-loaded THP-1 macrophages. Treatment with Ang-(1-7) led to a dose-dependent restoration of cholesterol efflux in the Ang II-treated cells. The co-treatment with Ang-(1-7) and Ang II significantly increased the expression levels of adenosine triphosphate (ATP)-binding cassette (ABC)A1 and ABCG1 compared with treatment with Ang II alone. This was coupled with increased expression levels of PPAR $\gamma$ and liver $X$ receptor (LXR) $\alpha$. The pharmacological inhibition of PPAR $\gamma$ significantly $(\mathrm{P}<0.05)$ eliminated the Ang-(1-7)-mediated induction of ABCA1 and ABCG1 mRNA expression. Treatment with Ang-(1-7) caused the inactivation of c-Jun N-terminal kinases (JNK) and p38 MAPK signaling in the Ang II-treated THP-1 macrophages. In addition, the inhibition of JNK or p38 MAPK signaling using specific pharmacological inhibitors mimicked the Ang-(1-7)-induced expression of PPAR $\gamma$ and LXR $\alpha$. In conclusion, the data demonstrated that treatment with Ang-(1-7) promoted cholesterol efflux in Ang II-treated THP-1 macrophages, partly
\end{abstract}

Correspondence to: Dr Zhi-Ming Yang, Department of Cardiology, The Second Hospital of Shanxi Medical University, 382 Wuyi Road, Taiyuan, Shanxi 030001, P.R. China

E-mail: zhimingyang800@sina.com

Key words: atherosclerosis, lipid accumulation, mitogen-activated protein kinase signaling, renin-angiotensin system through inactivation of $\mathrm{p} 38$ and JNK signaling and by inducing the expression of PPAR $\gamma$ and LXR $\alpha$. Ang (1-7) may, therefore, have therapeutic benefits for the treatment of atherosclerosis.

\section{Introduction}

Atherosclerosis is a progressive chronic inflammatory disease, characterized by the development of plaques in the artery, which ultimately lead to cardiovascular disease (1). One of the early events in atherogenesis is the formation of foam cells, which are macrophages containing ingested oxidized low-density lipoprotein (LDL) (2). It has been suggested that macrophages become foam cells as a consequence of the loss of the normal balance between cholesterol uptake from lipoproteins and cholesterol efflux. This has led to investigations to elucidate the regulation of cholesterol efflux from macrophages (3).

The adenosine triphosphate (ATP)-binding cassette $(\mathrm{ABC})$ transporters, $\mathrm{ABCA} 1$ and $\mathrm{ABCG} 1$, are important in the removal of cholesterol from lipid-laden macrophages as a primary anti-atherogenic mechanism (4). ABCA1 promotes cholesterol efflux from foam cells to lipid-free apolipoprotein A-1 (apoA-1), but not to mature high-density lipoprotein (HDL) particles, whereas ABCG1 mediates cholesterol efflux to HDL and not to the lipid-poor apoA-1 $(5,6)$. Biochemical studies have identified ABCA1 and ABCG1 as direct transcriptional targets of liver $\mathrm{X}$ receptor/retinoid $\mathrm{X}$ receptor (LXR/RXR) $(7,8)$. Peroxisome proliferator-activated receptor gamma $(\operatorname{PPAR} \gamma)$ is also involved in the transcriptional activation of the $\mathrm{ABC}$ transporters in an $\mathrm{LXR} \alpha$-dependent manner (9). Chawla et al (9) demonstrated that LXRo activation-induced expression levels of ABCA1 and ABCG1 are markedly reduced in PPAR $\gamma$-deficient macrophages, suggesting the involvement of PPAR $\gamma$ in the LXR $\alpha$-mediated upregulation of $\mathrm{ABC}$ proteins. PPAR $\gamma$ and LXR $\alpha$ have been demonstrated to exert anti-atherogenic effects by facilitating the removal of cholesterol from foam cells (10).

The renin-angiotensin system (RAS) is considered to be involved in the pathogenesis of atherosclerosis $(11,12)$. Angiotensin II (Ang II), the most important component of the RAS, has been found to promote the development of atherosclerosis in apolipoprotein-E (ApoE)-deficient mice (13). 
Ang-converting enzyme (ACE) 2 is a homolog of ACE, which is responsible for generating Ang II from Ang I. ACE2 efficiently degrades Ang II to form Ang-(1-7), a peptide exerting actions opposite to those of Ang II (14). Our previous study demonstrated that Ang-(1-7) ameliorates Ang-II-induced apoptosis in human umbilical vein endothelial cells (15). A previous study demonstrated that Ang-(1-7) dose-dependently inhibits early atherosclerotic lesions and increases plaque stability by targeting vascular cells in $\mathrm{ApoE}^{(-/)}$mice (16). Takata et al (17) reported that Ang II alters macrophage cholesterol homeostasis by repressing the expression of ABCA1, therefore, promoting foam cell formation. However, the effects of Ang-(1-7) on macrophage cholesterol metabolism remain to be elucidated. The present study investigated the effects of Ang-(1-7) on Ang II-stimulated cholesterol efflux and the associated molecular mechanisms.

\section{Materials and methods}

Reagents and antibodies. Ang II, Ang-(1-7), phorbol 12-my ristate 13-acetate (PMA), apoA-1, SB203580 (a p38 MAPK inhibitor), SP600125 (a JNK inhibitor) and GW9662 were purchased from Sigma-Aldrich (St. Louis, MO, USA). Primary mouse anti-human monoclonal antibodies (1:300) against ABCA1 (sc-53482), ABCG1 (sc-20795), PPAR $\gamma$ (sc-390740) and LXRa (sc-271064) were purchased from Santa Cruz Biotechnology, Inc. (Santa Cruz, CA, USA). Primary mouse or rabbit anti-human monoclonal antibodies (1:300) against total p38 (\#9212), phosphorylated (p-)p38 (\#9216), total extracellular signal-regulated protein kinases 1 and 2 (ERK1/2) (\#9102), p-ERK1/2 (\#9108), total c-Jun NH2-terminal kinase (JNK) (\#9252), p-JNK (\#9255) and $\beta$-actin (\#4967) were purchased from Cell Signaling Technology, Inc. (Beverly, MA, USA). Horseradish peroxidase-conjugated goat anti-mouse or antirabbit secondary antibodies (1:2,000 dilution) were purchased from Santa Cruz Biotechnology, Inc.

Culture and differentiation of THP-1 cells. Human THP-1 cells were purchased from the Cell Bank of Chinese Academy of Sciences (Shanghai, China) and cultured in RPMI-1640 medium, containing $10 \%$ fetal bovine serum (FBS), $10 \mu \mathrm{g} / \mathrm{ml}$ streptomycin and $100 \mathrm{U} / \mathrm{ml}$ penicillin (Invitrogen Life Technologies, Carlsbad, CA, USA) at $37^{\circ} \mathrm{C}$ with $5 \% \mathrm{CO}_{2}$. To differentiate these cells into macrophages, the monocytes were seeded into 12 -well plates at a density of $1 \times 10^{6}$ cells/well in complete RPMI-1640 medium containing 160 nM PMA and incubated for $24 \mathrm{~h}$ at $37^{\circ} \mathrm{C}$.

Drug treatment. The differentiated THP-1 macrophages were washed three times in phosphate-buffered saline (PBS; Invitrogen Life Technologies) and labeled by incubation for $48 \mathrm{~h}$ at $37^{\circ} \mathrm{C}$ in the presence of $(3 \mathrm{H})$ cholesterol $\left(0.37 \times 10^{9} \mathrm{~Bq} / 1\right.$; GE Healthcare, Piscataway, NJ, USA) in RPMI-1640 medium, supplemented with $10 \%$ FBS. Following washing three times in PBS, the labeled cells were treated with Ang II $(1 \mu \mathrm{M})$ and/or 10 or $100 \mathrm{nM}$ Ang-(1-7) (18) for $24 \mathrm{~h}$ at $37^{\circ} \mathrm{C}$. Unless stated otherwise, $100 \mathrm{nM}$ Ang-(1-7) was used. To investigate the role of PPAR $\gamma$ in the Ang-(1-7)-mediated induction of ABCA1 and ABCG1 expression, the THP-1 macrophages were treated with GW9662 $(1 \mu \mathrm{M})$ for $1 \mathrm{~h}$ (19), prior to incubation for $24 \mathrm{~h}$ with
$1 \mu \mathrm{M}$ Ang II with or without $100 \mathrm{nM}$ Ang-(1-7). To investigate the role of mitogen-activated protein kinases (MAPKs) in the regulation of PPAR $\gamma$ and LXR $\alpha$ expression, SB203580 $(10 \mu \mathrm{M})$ and/or SP600125 $(10 \mu \mathrm{M})(20)$ were added to the cell culture and incubated for $1 \mathrm{~h}$ at $37^{\circ} \mathrm{C}$ prior to the addition of $1 \mu \mathrm{M}$ Ang II.

Cholesterol efflux assay. Following the treatment described above, the labeled cells were washed three times in PBS and incubated in serum-free RPMI-1640 medium containing $10 \mathrm{mg} / 1$ apoA-1 as a cholesterol receptor for $12 \mathrm{~h}$ at $37^{\circ} \mathrm{C}$. The medium was then collected and centrifuged at $1,000 \mathrm{x} \mathrm{g}$ for $10 \mathrm{~min}$ at room temperature to remove cellular debris. Radioactivity in the medium and cells was analyzed by liquid scintillation counting (ZX34-LS6500; Beckman Coulter, Inc., Fullerton, CA, USA). The percentage of cholesterol efflux was calculated as: Counts/min (cpm) in the medium / (cpm in the cell + cpm in the medium) $\mathrm{x} 100$.

Reverse transcription-quantitative polymerase chain reaction $(R T-q P C R)$. The total RNA was extracted using TRIzol reagent, according to the manufacturer's instructions (Invitrogen Life Technologies). RT was performed using an AMV First Strand cDNA Synthesis kit (Bio Basic, Inc., Amhurst, NY, USA). qPCR amplification was performed using an Applied Biosystems StepOnePlus Real-Time PCR system (Applied Biosystems, Foster City, CA, USA) using a SYBR green PCR master mix (Applied Biosystems). The primers used for qPCR are listed in Table I. Each PCR reaction $(20 \mu \mathrm{l})$ contained $10 \mathrm{ng}$ cDNA and ther thermal cyclin conditions were as follows: $95^{\circ} \mathrm{C}$ for $10 \mathrm{~min}$, followed by 35 cycles of $95^{\circ} \mathrm{C}$ for $15 \mathrm{sec}$ and $60^{\circ} \mathrm{C}$ for $50 \mathrm{sec}$. As an internal quantitative control, glyceraldehyde 3-phosphate dehydrogenase (GAPDH) was amplified in a parallel reaction. All assays were performed in triplicate and the threshold cycle $(\mathrm{Ct})$ value was determined as the cycle number at which the fluorescence signal reached the exponential phase. The relative mRNA expression levels were normalized against GAPDH and were determined using the $2^{-\Delta \Delta C t}$ method (21).

Western blot analysis. Following treatment, the cells were lysed in lysis buffer (Santa Cruz Biotechnology, Inc.), containing $50 \mathrm{mmol} / \mathrm{l}$ Tris (pH 7.4), $150 \mathrm{mmol} / 1 \mathrm{NaCl}, 1 \% \mathrm{NP}-40$ and $0.1 \%$ sodium dodecyl sulphate (SDS; Sigma-Aldrich), supplemented with protease and phosphatase inhibitors, including pepstatin, leupeptin, aprotinin and phenylmethylsulfonyl fluoride, which were purchased from Sigma-Aldrich. The protein samples were separated on polyacrylamide gels (Bio-Rad Laboratories, Inc., Hercules, CA, USA) containing 0.1\% SDS, and then transferred onto a nitrocellulose membrane (Millipore, Bedford, MA, USA). Following blocking for $4 \mathrm{~h}$ in a Tris-buffered solution, containing 5\% non-fat dried milk and $0.5 \%$ Tween-20 (Sigma-Aldrich), the membrane was incubated with individual primary antibodies (1:300; as described above) overnight at $4^{\circ} \mathrm{C}$. The membrane was then washed three times in PBS and incubated for $1 \mathrm{~h}$ with secondary antibodies at room temperature. The signals were visualized using the enhanced chemiluminescence detection system (Amersham Biosciences, Little Chalfont, UK) and developed on X-ray film (GE Healthcare). The band density was measured using the 
Table I. Primer sequences for reverse transcription-quantitative polymerase chain reaction.

\begin{tabular}{clc}
\hline Gene & \multicolumn{1}{c}{ Sequence $\left(5^{\prime}-3^{\prime}\right)$} & $\begin{array}{c}\text { Primer } \\
\text { size }(\mathrm{bp})\end{array}$ \\
\hline ABCA1 & & \\
Forward & GCTTTCAATCATCCCCTGAA & 20 \\
Reverse & TGACAGGCTTCACTCCACTG & 20 \\
ABCG1 & & \\
Forward & CTCCGGCTTCCTCTTCTTCT & 20 \\
Reverse & TACACGATGCTGCAGTAGGC & 20 \\
PPAR $\gamma$ & & \\
Forward & GAGCCCAAGTTTGAGTTTGC & 20 \\
Reverse & CTGTGAGGACTCAGGGTGGT & 20 \\
LXR $\underline{\alpha}$ & & \\
Forward & ACGGTGATGCTTCTGGAGAC & 20 \\
Reverse & AGCAATGAGCAAGGCAAACT & 20 \\
GAPDH & & \\
Forward & CGACCACTTTGTCAAGCTCA & 20 \\
Reverse & AGGGGAGATTCAGTGTGGTG & 20 \\
\hline
\end{tabular}

ABCA1, adenosine triphosphate-binding cassette, sub-family A member 1; ABCG1, ATP-binding cassette sub-family G member 1; PPAR $\alpha$, peroxisome proliferator-activated receptor $\gamma$; LXR $\underline{\alpha}$, liver X receptor $\underline{\alpha}$.

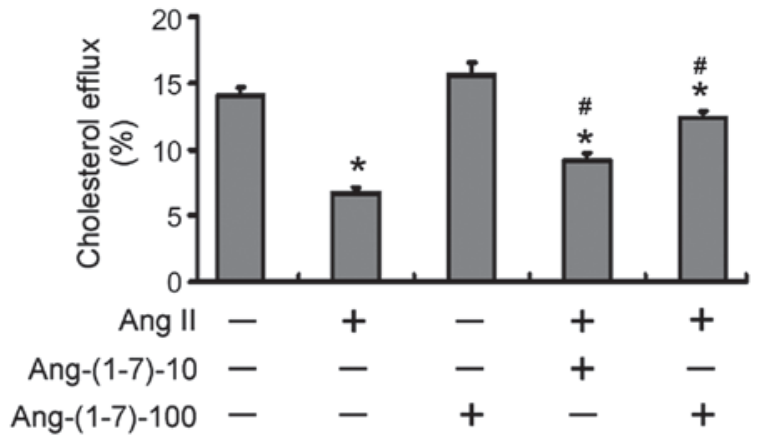

Figure 1. Effects of Ang-(1-7) on cholesterol efflux from Ang II-treated THP-1 macrophages. Differentiated THP-1 macrophages were labeled by incubation for $48 \mathrm{~h}$ in the presence of $(3 \mathrm{H})$ cholesterol and treated with Ang II and/or Ang-(1-7) for a further $24 \mathrm{~h}$. Following treatment, the efflux of cholesterol to apoA-1 was measured. The data are expressed as the mean \pm standard deviation of three independent experiments ( $\mathrm{P}<0.05$, vs. untreated cells ${ }^{\#} \mathrm{P}<0.05$, vs. Ang II-only cells). Ang-(1-7)-10 and Ang-(1-7)-100 indicate treatment with 10 or $100 \mathrm{nM}$ Ang-(1-7), respectively. Ang, angiotensin.

GelDoc 2000 system equipped with Quantity One 4.6 software (Bio-Rad Laboratories, Inc.) and normalized against $\beta$-actin.

Statistical analysis. The data are expressed as the mean \pm standard deviation. All statistical analyses were performed using SPSS 19.0 software (IBM, Armonk, NY, USA). Statistical differences among multiple groups were calculated using a one-way analysis of variance followed by Tukey's post-hoc test. $\mathrm{P}<0.05$ was considered to indicate a statistically significant difference.
A

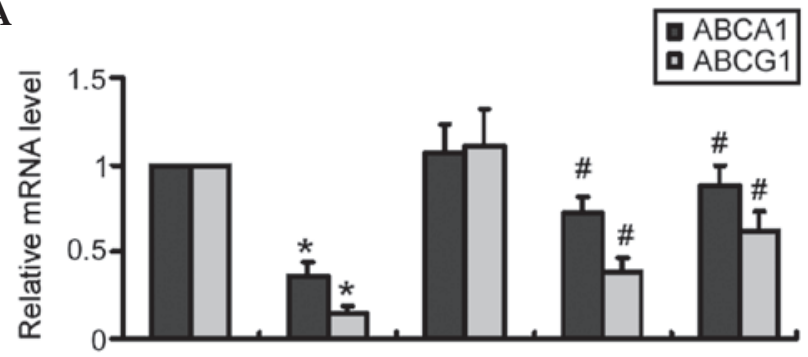

B

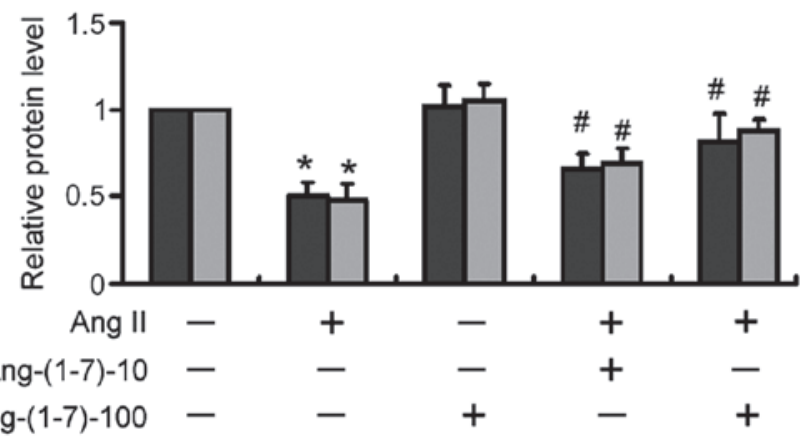

Figure 2. Effects of Ang-(1-7) on the expression levels of ABCA1 and ABCG1 in Ang II-treated THP-1 macrophages. Differentiated THP-1 macrophages were treated with Ang II and/or Ang-(1-7) for $24 \mathrm{~h}$ and the (A) mRNA and (B) protein expression levels of ABCA1 and ABCG1 were determined by reverse transcription-quantitative polymerase chain reaction and western blot analysis, respectively. The data are expressed as the mean \pm standard deviation of three independent experiments ( $\mathrm{P}<0.05$, vs. untreated cells; ${ }^{\#} \mathrm{P}<0.05$, vs. Ang II-only cells). Ang-(1-7)-10 and Ang-(1-7)-100 indicate treatment with 10 or $100 \mathrm{nM}$ Ang-(1-7), respectively. Ang, angiotensin; ABC, adenosine triphosphate-binding cassette transporters.

\section{Results}

Ang-(1-7) antagonizes the Ang II-mediated repression of cholesterol efflux. Compared with the untreated control THP-1 macrophages, treatment with Ang II $(1 \mu \mathrm{M})$ for $48 \mathrm{~h}$ significantly reduced the rate of cholesterol efflux to apoA-1 by $\sim 50 \%(7.69 \pm 0.48$, vs. $14.06 \pm 0.56 \%$; P<0.05; Fig. 1$)$, Notably, treatment with Ang-(1-7) led to a dose-dependent restoration in cholesterol efflux to apoA-1. When the cells were treated with $100 \mathrm{nM}$ Ang-(1-7), the cholesterol efflux rate $(12.39 \pm 0.50)$ increased to a level similar to that observed in the control group.

Ang-(1-7) relieves the Ang II-mediated suppression of the gene expression levels of $A B C A 1$ and $A B C G 1$. The mRNA expression levels of ABCA1 and ABCG1 were significantly $(\mathrm{P}<0.05)$ reduced in the Ang II-treated THP-1 macrophages compared with the control cells (Fig. 2A). The co-treatment with Ang-(1-7) and Ang II significantly increased the mRNA expression levels of ABCA1 and ABCG1 in a dose-dependent manner $(\mathrm{P}<0.05)$, compared with Ang II only (Fig. 2A). In addition, western blot analysis revealed that treatment with Ang-(1-7) significantly $(\mathrm{P}<0.05)$ attenuated the Ang II-mediated reduction in the protein expression levels of ABCA1 and ABCG1 in a dose-dependent manner (Fig. 2B).

Ang-(1-7) restores the expression levels of PPAR $\gamma$ and LXR $\alpha$ in Ang II-treated cells. Treatment with Ang II alone 
A

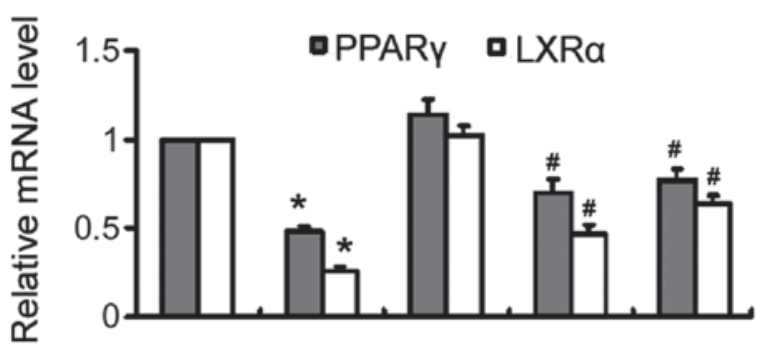

B
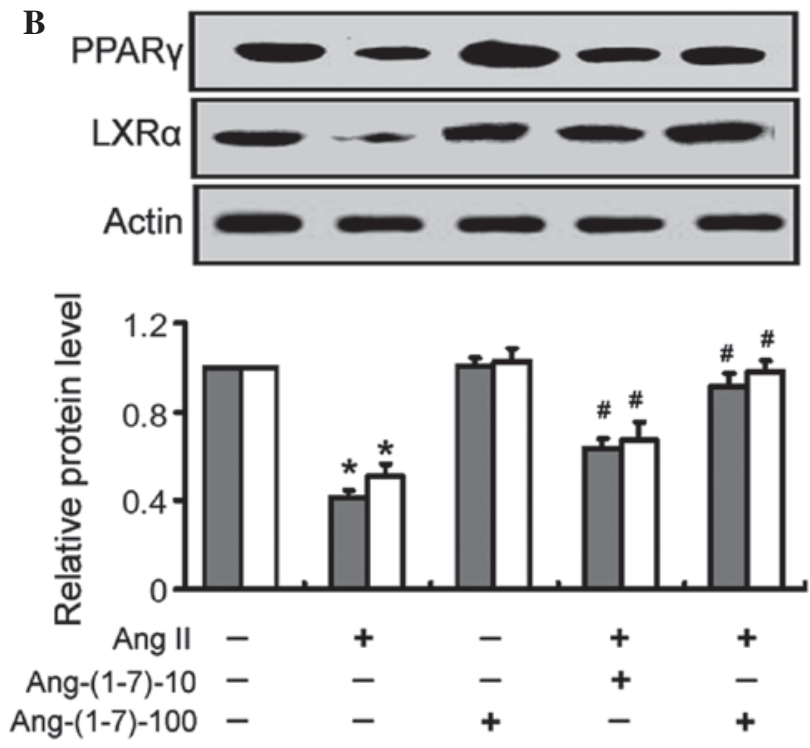

Figure 3. Ang-(1-7) stimulates the expression levels of PPAR $\not$ and $\mathrm{LXR} \underline{\alpha}$ in Ang II-treated THP-1 macrophages. The THP-1 macrophages were treated with Ang II and/or Ang-(1-7) for 24 h. (A) Reverse transcription quantitative polymerase chain reaction analysis of the mRNA expression levels of PPAR $\gamma$ and $\mathrm{LXR} \alpha$ and (B) western blot analysis of the protein expression levels of PPAR $\gamma$ and LXR $\alpha$. were performed. Representative blots of three independent experiments and densitometric quantification of the blots are shown ( $\mathrm{P}<0.05$, vs. untreated cells; ${ }^{\#} \mathrm{P}<0.05$, vs. Ang II-only cells). Ang-(1-7)-10 and Ang-(1-7)-100 indicate treatment with 10 or $100 \mathrm{nM}$ Ang-(1-7), respectively. PPAR, peroxisome proliferator-activated receptor; LXR, liver X receptor; Ang, angiotensin.

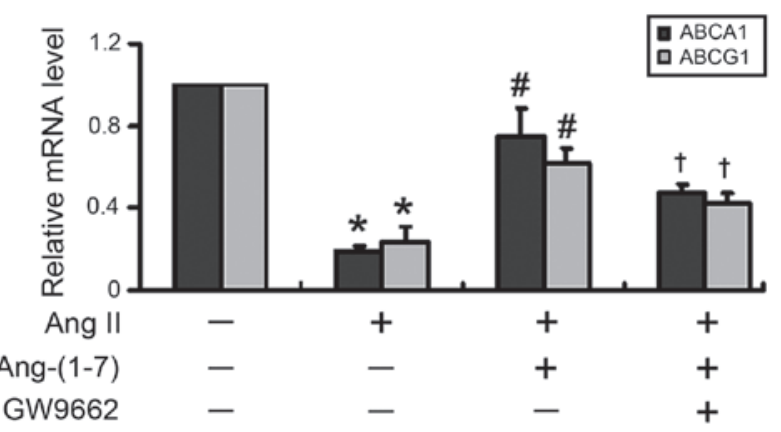

Figure 4. Pharmacological inactivation of PPAR $\gamma$ reverses the inductive effects of Ang-(1-7) on the expression levels of ABCA1 and ABCG1. The THP-1 macrophages were treated with Ang II with or without Ang-(1-7) with or without pretreatment with the PPAR $\chi$ inhibitor, GW9662. Following incubation for $24 \mathrm{~h}$, the mRNA expression $\neq$ levels of ABCA1 and ABCG1 were determined by reverse transcription-quantitative polymerase chain reaction. The data are expressed as the mean \pm standard deviation of three independent experiments $\left({ }^{*} \mathrm{P}<0.05\right.$, vs. untreated cells; ${ }^{*} \mathrm{P}<0.05$, vs. Ang II-only-cells; ${ }^{\dagger} \mathrm{P}<0.05$, vs. cells treated with Ang II and Ang-1-7). ABC, adenosine triphosphate-binding cassette transporter; Ang, angiotensin; PPAR, peroxisome proliferator-activated receptor. significantly $(\mathrm{P}<0.05)$ reduced the mRNA expression levels of PPAR $\gamma$ and LXR $\alpha$ in the THP-1 macrophages, compared with the control cells (Fig. 3A). Treatment with Ang-(1-7) inhibited the Ang II-mediated suppression of PPAR $\gamma$ and LXR $\alpha$ expression in a dose-dependent manner (Fig. 3A). Similarly, the Ang II-mediated reduction in the protein expression of PPAR $\gamma$ and LXR $\alpha$ was almost completely inhibited following treatment with Ang-(1-7), as determined by western blot analysis (Fig. 3B).

Pharmacological inactivation of PPAR $\gamma$ attenuates the stimulatory effects of Ang-(1-7) on the mRNA expression levels of $A B C A 1$ and $A B C G 1$. Subsequently, the present study inhibited the activity of PPAR $\gamma$ to investigate whether the Ang-(1-7)-mediated stimulation of ABCA1 and ABCG1 expression was PPAR $\gamma$-dependent. As shown in Fig. 4, inhibition of PPAR $\gamma$ with GW9662, an irreversible and selective PPAR $\gamma$ antagonist, significantly $(\mathrm{P}<0.05)$ eliminated the Ang-(1-7)-mediated induction of the mRNA expression of ABCA1 and ABCG1.

Inactivation of JNK and p38 MAPKs is associated with the Ang-(1-7)-mediated induction of PPAR $\gamma$ and LXR $\alpha$ expression. To elucidate the mechanisms underlying the Ang-(1-7)-induced expression of PPAR $\gamma$ and LXR $\alpha$, MAPK signaling pathways were investigated by western blot analysis. It was revealed that treatment with Ang-(1-7) significantly $(\mathrm{P}<0.05)$ antagonized the inductive effect of Ang II on the phosphorylation of JNK and p38 MAPKs, but not ERK1/2 (Fig. 5A). The total protein expression levels of the MAPKs were not affected by treatment with Ang-(1-7). Notably, co-incubation with SB203580, a specific inhibitor of p38 MAPK, significantly $(\mathrm{P}<0.05)$ restored the expression levels of PPAR $\gamma$ and LXR $\alpha$ in Ang II-treated THP-1 macrophages (Fig. 5B), which mimicked the indusive effects of Ang-(1-7). Similarly, inhibition of JNK signaling using SP600125 significantly $(\mathrm{P}<0.05)$ attenuated the inhibition of PPAR $\gamma$ and LXR $\alpha$ expression by Ang II. Taken together, these results suggested that inactivation of p38 and JNK MAPK signaling was involved in the Ang-(1-7)-mediated induction of PPAR $\gamma$ and $\mathrm{LXR} \alpha$ expression.

\section{Discussion}

Ang II ha been implicated in a variety of cardiovascular diseases, including atherosclerosis, hypertension, left ventricular hypertrophy, myocardial infarction and heart failure (22). It has been demonstrated that Ang II accelerates foam cell formation by upregulating the expression of acyl-coenzyme A:cholesterol acyltransferase-1 (ACAT1), which converts intracellular free cholesterol into cholesterol ester for storage in lipid droplets (23). In addition, the upregulation of ACAT1, suppression of ABCA1 expression and subsequent cholesterol transport is known to mediate the atherosclerotic effect of Ang II (24). Consistently, the present study demonstrated that treatment with Ang II resulted in a significant reduction in cholesterol efflux from the THP-1 foam cells to apoA-1. This inhibition of cholesterol accumulation was coupled with the downregulation of ABCA1 and ABCG1. Notably, the presence of Ang-(1-7) significantly reversed the Ang II-induced repression of cholesterol efflux. Taken together, these results provided evidence that Ang-(1-7) 
A
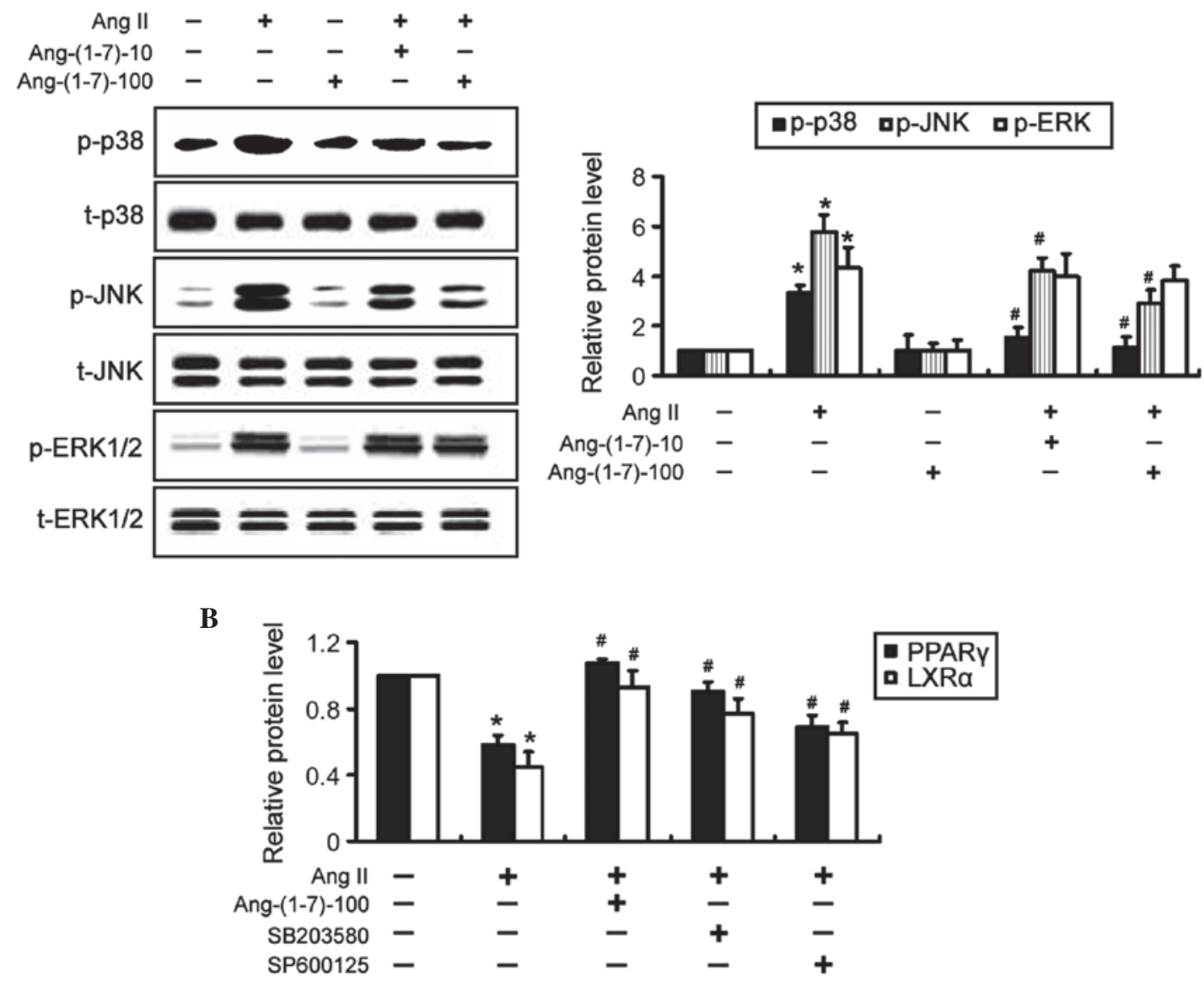

Figure 5. Ang-(1-7)-mediated induction of PPAR $\underline{\alpha}$ and LXR $\underline{\alpha}$ is associated with the suppression of JNK and p38 mitogen-activated protein kinase activation. (A) THP-1 macrophages were exposed to Ang II and/or Ang-(1-7) for $24 \mathrm{~h}$ and the phosphorylation levels of MAPKs were examined by western blot analysis. Representative blots of three independent experiments and densitometric quantification of the blots are shown. (B) THP-1 macrophages were treated with $10 \mu \mathrm{M} \mathrm{SB} 203580$ or SP600125 for $1 \mathrm{~h}$ prior to the addition of $1 \mu \mathrm{M}$ Ang II. Following treatment, the protein expression levels of PPAR $\gamma$ and LXR $\underline{\alpha}$ were determined by western blot analysis. The data are expressed as the mean \pm standard deviation of three independent experiments ( $\mathrm{P}<0.05$, vs. untreated cells; ${ }^{\#} \mathrm{P}<0.05$ vs. Ang II-only cells). Ang-(1-7)-10 and Ang-(1-7)-100 indicate treatment with 10 or 100 nM Ang-(1-7), respectively. Ang, angiotensin; p-, phosphorylated; t-, total; JNK, c-Jun NH2-terminal kianse; ERK, extracellular signal-regulated kinase; PPAR, peroxisome proliferator-activated receptor; LXR $\alpha$, liver X receptor $\alpha$.

and Ang II exhibited counter-regulatory roles in macrophage cholesterol homeostasis.

The present study revealed that treatment with Ang II caused a significant decrease in the mRNA expression levels of ABCA1 and $A B C G 1$, suggesting its importance in transcriptional regulation. Notably, co-treatment with Ang-(1-7) significantly restored the expression levels of ABCA1 and ABCG1 in the Ang II-treated THP-1 macrophages. Since PPAR $\gamma$ and LXR $\alpha$ are the 'master' transcription factors, cooperatively regulate the expression levels of ABCA1 and ABCG1 $(8,9)$, the present study assessed the effects of Ang-(1-7) on the expression levels of PPAR $\gamma$ and LXR $\alpha$. It was found that the Ang II-mediated suppression of t PPAR $\gamma$ and $\operatorname{LXR} \alpha$ expression was significantly reversed following treatment with Ang-(1-7). The Ang-(1-7)-mediated induction of PPAR $\gamma$ expression has also been demonstrated in other biological contexts $(25,26)$. Dhaunsi et al (26) reported that treatment with Ang-(1-7) prevents the inhibition of PPAR $\gamma$ expression in diabetes and/or hypertension. The present study further demonstrated that the pharmacological inhibition of PPAR $\gamma$ with GW9662 significantly inhibited the Ang-(1-7)-mediated induction of ABCA1 and ABCG1 mRNA expression. These results suggested that treatment with
Ang-(1-7) facilitated the PPAR $\gamma$-dependent transcriptional activation of the ABC genes, which provided a possible explanation for its promotion of cholesterol efflux from foam cells.

There is evidence that MAPK signaling is involved in foam cell formation (27-29). Ren et al (27) demonstrated that oxidized HDL accelerates foam cell formation via the p38 MAPK-dependent upregulation of PPAR $\gamma$ and downregulation of cluster of differentiation 36. Mei et al (29) demonstrated that activation of p38 MAPK promotes cholesterol ester accumulation in macrophages. Pharmacological inhibition of p38 MAPK signaling, including treatment with curcumin, has also been revealed to hinder oxidized LDL-induced foam cell formation (30). In addition to p38 MAPK, activation of the JNK MAPK is involved in foam cell formation from macrophages, which are exposed to oxidized LDL (31). In agreement with previous studies, the present study revealed that the Ang-(1-7)-mediated promotion of cholesterol efflux in Ang II-treated THP-1 macrophages is coupled with the inactivation of JNK and p38 MAPK signaling. Additionally, the inhibition of MAPK signaling using specific pharmacological inhibitors mimicked the induction of PPAR $\gamma$ and LXR $\alpha$ expression by Ang-(1-7). These results suggested that the Ang-(1-7)-mediated 
restoration of PPAR $\gamma$ and LXR $\alpha$ expression was associated, in part, with the suppression of MAPK signaling. The inhibition of MAPK signaling by Ang-(1-7) has also been demonstrated in other biological settings. Santos et al (32) reported that oral treatment with Ang-(1-7) prevents obesity and hepatic inflammation in high-fat fed rats, which is associated with the suppression of the MAPK signaling pathway. Moon et al (33) revealed that Ang II-induced MAPK signaling activation is attenuated by Ang-(1-7) in mesangial cells.

In conclusion, the present study provided the first evidence, to the best of our knowledge, that Ang-(1-7) facilitated cholesterol efflux in Ang II-treated THP-1 macrophages, which, in part, involved the suppression of p38 and JNK signaling and the induction of PPAR $\gamma$ and LXR $\alpha$ expression. These findings suggested that Ang-(1-7) may offer therapeutic benefits in preventing the development of atherosclerosis.

\section{Acknowledgements}

This study was published as an abstract in J Am Coll Cardiol 64: S6, 2014. The present study was supported by grants from the Scientific and Technological Project of Shanxi Province of China (no. 20100311098-4), the Doctoral Foundation of The Second Hospital of Shanxi Medical University of China (no. 20100404), the Youth Foundation of Shanxi Medical University of China (no. 02201421) and the Youth Foundation of Health and Family Planning Commission of Shanxi Province of China (no. 2014041).

\section{References}

1. Libby P, Ridker PM and Maseri A: Inflammation and atherosclerosis. Circulation 105: 1135-1143, 2002.

2. Fenyo IM and Gafencu AV: The involvement of the monocytes/macrophages in chronic inflammation associated with atherosclerosis. Immunobiology 218: 1376-1384, 2013

3. Yu XH, Fu YC, Zhang DW, Yin K and Tang CK: Foam cells in atherosclerosis. Clin Chim Acta 424: 245-252, 2013.

4. Yvan-Charvet L, Wang N and Tall AR: Role of HDL, ABCA1, and ABCG1 transporters in cholesterol efflux and immune responses. Arterioscler Thromb Vasc Biol 30: 139-143, 2010.

5. Smith JD, Le Goff W, Settle M, Brubaker G, Waelde C, Horwitz A and Oda MN: ABCA1 mediates concurrent cholesterol and phospholipid efflux to apolipoprotein A-I. J Lipid Res 45: 635-644, 2004.

6. Matsuura F, Wang N, Chen W, Jiang XC and Tall AR: HDL from CETP-deficient subjects shows enhanced ability to promote cholesterol efflux from macrophages in an apoE- and ABCG1-dependent pathway. J Clin Invest 116: 1435-1442, 2006.

7. Costet P, Luo Y, Wang N and Tall AR: Sterol-dependent transactivation of the $\mathrm{ABC} 1$ promoter by the liver $\mathrm{X}$ receptor/retinoid $\mathrm{X}$ receptor. J Biol Chem 275: 28240-28245, 2000.

8. Kennedy MA, Venkateswaran A, Tarr PT, Xenarios I, Kudoh J, Shimizu N and Edwards PA: Characterization of the human ABCG1 gene: liver $X$ receptor activates an internal promoter that produces a novel transcript encoding an alternative form of the protein. J Biol Chem 276: 39438-39447, 2001.

9. Chawla A, Boisvert WA, Lee CH, et al: A PPAR $\gamma-\mathrm{LXR}-\mathrm{ABCA} 1$ pathway in macrophages is involved in cholesterol efflux and atherogenesis. Mol Cell 7: 161-171, 2001.

10. Nagy ZS, Czimmerer Z and Nagy L: Nuclear receptor mediated mechanisms of macrophage cholesterol metabolism. Mol Cell Endocrinol 368: 85-98, 2013

11. Wang Y, Tikellis C, Thomas MC and Golledge J: Angiotensin converting enzyme 2 and atherosclerosis. Atherosclerosis 226 : $3-8,2013$

12. Kawahito H, Yamada H, Irie D, et al: Periaortic adipose tissue-specific activation of the renin angiotensin system contributes to atherosclerosis development in uninephrectomized apoE-/- mice. Am J Physiol Heart Circ Physiol 305: H667-H675, 2013.
13. Fujisaka T, Hoshiga M, Hotchi J, et al: Angiotensin II promotes aortic valve thickening independent of elevated blood pressure in apolipoprotein-E deficient mice. Atherosclerosis 226: 82-87, 2013

14. Santos RA, Ferreira AJ, Verano-Braga T and Bader M: Angiotensin-converting enzyme 2, angiotensin-(1-7) and Mas: new players of the renin-angiotensin system. J Endocrinol 216: R1-R17, 2013

15. Yang HY, Bian YF, Zhang HP, et al: Angiotensin-(1-7) treatment ameliorates angiotensin II-induced HUVEC apoptosis. Clin Exp Pharmacol Physiol 39: 1004-1010, 2012.

16. Yang JM, Dong M, Meng X, et al: Angiotensin-(1-7) dose-dependently inhibits atherosclerotic lesion formation and enhances plaque stability by targeting vascular cells. Arterioscler Thromb Vasc Biol 33: 1978-1985, 2013.

17. Takata Y, Chu V, Collins AR, et al: Transcriptional repression of ATP-binding cassette transporter A1 gene in macrophages: a novel atherosclerotic effect of angiotensin II. Circ Res 97: e88-e96, 2005.

18. Sampaio WO, Souza dos Santos RA, Faria-Silva R, da Mata Machado LT, Schiffrin EL and Touyz RM: Angiotensin-(1-7) through receptor Mas mediates endothelial nitric oxide synthase activation via Akt-dependent pathways. Hypertension 49: 185-192, 2007.

19. Hwang JS, Kang ES, Ham SA, et al: Activation of peroxisome proliferator-activated receptor $\gamma$ by rosiglitazone inhibits lipopolysaccharide-induced release of high mobility group box 1 . Mediators Inflamm 2012: 352807, 2012.

20. Trasino SE, Kim YS and Wang TT: Ligand, receptor, and cell type-dependent regulation of ABCA1 and ABCG1 mRNA in prostate cancer epithelial cells. Mol Cancer Ther 8: 1934-1945, 2009.

21. Livak KJ and Schmittgen TD: Analysis of relative gene expression data using real-time quantitative PCR and the $2(-\Delta \Delta \mathrm{C}(\mathrm{T}))$ Method. Methods 25: 402-408, 2001.

22. RosenbaughEG, Savalia KK, Manickam DS andZimmerman MC: Antioxidant-based therapies for angiotensin II-associated cardiovascular diseases. Am J Physiol Regul Integr Comp Physiol 304: R917-R928, 2013.

23. Kanome T, Watanabe T, Nishio K, Takahashi K, Hongo S and Miyazaki A: Angiotensin II upregulates acyl-CoA:cholesterol acyltransferase-1 via the angiotensin II Type 1 receptor in human monocyte-macrophages. Hypertens Res 31: 1801-1810, 2008.

24. Wang Y, Chen Z, Liao Y, et al: Angiotensin II increases the cholesterol content of foam cells via down-regulating the expression of ATP-binding cassette transporter A1. Biochem Biophys Res Commun 353: 650-654, 2007.

25. Mario EG, Santos SH, Ferreira AV, Bader M, Santos RA and Botion LM: Angiotensin-(1-7) Mas-receptor deficiency decreases peroxisome proliferator-activated receptor $\gamma$ expression in adipocytes. Peptides 33: 174-177, 2012.

26. Dhaunsi GS, Yousif MH, Akhtar S, Chappell MC, Diz DI and Benter IF: Angiotensin-(1-7) prevents diabetes-induced attenuation in PPAR-gamma and catalase activities. Eur J Pharmacol 638: 108-114, 2010.

27. Ren J, Jin W and Chen H: oxHDL decreases the expression of CD36 on human macrophages through PPARgamma and p38 MAP kinase dependent mechanisms. Mol Cell Biochem 342: 171-181, 2010.

28. Rohde E, Schallmoser K, Reinisch A, et al: Pro-angiogenic induction of myeloid cells for therapeutic angiogenesis can induce mitogen-activated protein kinase $\mathrm{p} 38$-dependent foam cell formation. Cytotherapy 13: 503-512, 2011.

29. Mei S, Gu H, Ward A, et al: p38 mitogen-activated protein kinase (MAPK) promotes cholesterol ester accumulation in macrophages through inhibition of macroautophagy. J Biol Chem 287: 11761-11768, 2012.

30. Min KJ, Um HJ, Cho KH and Kwon TK: Curcumin inhibits oxLDL-induced CD36 expression and foam cell formation through the inhibition of p38 MAPK phosphorylation. Food Chem Toxicol 58: 77-85, 2013.

31. Yin R, Dong YG and Li HL: PPAR $\gamma$ phosphorylation mediated by JNK MAPK: a potential role in macrophage-derived foam cell formation. Acta Pharmacol Sin 27: 1146-1152, 2006.

32. Santos SH, Andrade JM, Fernandes LR, et al: Oral Angiotensin-(1-7) prevented obesity and hepatic inflammation by inhibition of resistin/TLR4/MAPK/NF- $\mathrm{BB}$ in rats fed with high-fat diet. Peptides 46: 47-52, 2013.

33. Moon JY, Tanimoto M, Gohda T, et al: Attenuating effect of angiotensin-(1-7) on angiotensin II-mediated NAD(P)H oxidase activation in type 2 diabetic nephropathy of KK-A(y)/Ta mice. Am J Physiol Renal Physiol 300: F1271-F1282, 2011. 